\title{
Nickel (II) removal using modified Citrus limettioides peel
}

\author{
R. Sudha $\cdot$ K. Srinivasan
}

Received: 23 May 2014/Revised: 11 January 2015/Accepted: 15 February 2015/Published online: 4 March 2015

(C) Islamic Azad University (IAU) 2015

\begin{abstract}
The $\mathrm{Ni}$ (II) adsorption capacity of carbon derived from Citrus limettioides peel (CLP), which is a novel waste material (CLPC), was evaluated regarding contact time, $\mathrm{pH}$ and adsorbent dose during batch adsorption processes with raw CLP. The optimal contact time for the adsorption of $\mathrm{Ni}$ (II) ions onto the peel and peel carbon was $3 \mathrm{~h}$, and the optimal $\mathrm{pH}$ ranged from 5.0 to 8.0 for CLP and $4.0-8.0$ for CLPC, respectively. The removal percentage decreased from 85.0 to $70.0 \%$ for CLP and remained nearly constant (99\%) for CLPC when the initial $\mathrm{Ni}(\mathrm{II})$ concentration was increased from 10 to $50 \mathrm{mg} \mathrm{L}^{-1}$. The equilibrium data fit the Langmuir isotherm with a high $R^{2}$ value, indicating that the $\mathrm{Ni}(\mathrm{II})$ ions formed a homogenous monolayer on the adsorbent surface. Adsorption capacity of $\mathrm{Ni}(\mathrm{II})$ ions on peel (CLP) and peel carbon (CLPC) was found to be 25.64 and $38.46 \mathrm{mg} \mathrm{g}^{-1}$, respectively. The surface morphology and functionality of the CLP and CLPC before and after adsorption were characterized using SEM, EDX and FT-IR. Various thermodynamic parameters, including the standard Gibbs free energy $\left(\Delta G^{\circ}\right)$, standard enthalpy $\left(\Delta H^{\circ}\right)$ and standard entropy $\left(\Delta S^{\circ}\right)$, were evaluated. The CLP and CLPC were tested with $\mathrm{Ni}$ (II) plating wastewater through a batch-mode process over five cycles; CLPC showed better results than CLP.
\end{abstract}

Keywords Adsorption - Citrus limettioides - Isotherm . Thermodynamic parameters

R. Sudha $(\bowtie) \cdot$ K. Srinivasan

Gnanamani College of Technology, Pachal, Namakkal 637018, India

e-mail: sudhar8680@gmail.com

\section{Introduction}

Heavy metal contamination in the environment caused by industrial and technological activities is an increasing economic, public health and environmental problem (Nwuche and Ugoji 2008). Divalent nickel [Ni(II)] causes major concern due to its various industrial uses, high toxicity and recalcitrance (Shroff and Vaidya 2011). Industrial discharges from nickel electroplating units, batteries, accumulator and stainless steel manufacturing plants, paint formulation, porcelain enameling, ceramic, mining, metallurgy and steam-electric power plants usually contain high amounts of $\mathrm{Ni}(\mathrm{II})$ ions, which are toxic toward microorganisms, plants and animals including human beings (Flores-Garnica et al. 2013). Acute and chronic nickel poisoning causes headaches, nausea, vomiting, dizziness, chest pain and tightness, cyanosis, skin dermatitis, rapid respiration, pulmonary fibrosis, and renal edema, as well as severe damage to the lungs, kidney, nervous system and mucous membranes (Pandey et al. 2007; Subbaiah et al. 2009). Moreover, nickel is carcinogenic and has been implicated as a nephrotoxin (Savolainen 1996), a teratogen and an embryotoxin (Pandey et al. 2007). Therefore, removing $\mathrm{Ni}(\mathrm{II})$ ions from industrial wastewaters is essential for maintaining public health.

Many methods, such as chemical precipitation, coagulation and flocculation, ion exchange, reverse osmosis, and membrane separation, electrochemical reduction and biological treatment, have been developed to remove nickel from wastewater (Lin et al. 2000). However, these technologies require expensive treatment and disposal of the secondary toxic metal sludge or remain ineffective when nickel is present in the wastewater at low concentrations. Currently, activated carbon adsorption is a commonly used technology because it is simple, inexpensive 
and effective for removing low nickel concentrations and any organic matter in waste streams (Bhatnagar and Minocha 2010; Mahvi 2008).

Activated carbon derived from various agricultural waste products, such as almond husks (Hasar 2003), peanut shells (Wilson et al. 2006), guava seeds (Zewail and ElGarf 2010), tamarind nuts (Suganthi and Srinivasan 2011), apricot stones (Kobya et al. 2005), olive stone (Ugurlu et al. 2009; Tamer M. Alslaibi et al. 2014), cottonseed cakes (Ozbay 2009), coconut oil cakes (Hema and Srinivasan 2010), palm shell (Onundi et al. 2010), peganum harmala-L (Ghasemi et al. 2014a, b), Lycopersicum esculentum (Tomato) leaf powder (Gutha et al. 2014), pine apple and bamboo stem (Rajesh et al. 2014), have been successfully applied toward nickel (II) removal.

Citrus Limettioides is an inexpensive, nutritious fruit consumed in rural areas; this species belongs to the $\mathrm{Ru}$ taceae family. The acids extracted from this fruit are used as flavorings and preservatives in food and beverages, particularly soft drinks, while the peel is considered a waste material. The Citrus limettioides fruit is primarily composed of d-limonene, myrcene, citronellal and $\beta$-citronellol (Jayaprakasha et al. 2013).

This study examines the activated carbon prepared from Citrus limettioides peel (CLP) and the raw peel for the removal of $\mathrm{Ni}$ (II) from aqueous solutions and industrial plating wastewater. The adsorption parameters, including the contact time, $\mathrm{pH}$, adsorbent dose, isothermal studies and thermodynamic properties, were investigated. This research was carried out from July 2013 to August 2014 at the Environmental Research Laboratory, Department of Chemistry, Gnanamani College of Technology, Rasipuram, Tamil Nadu, India.

\section{Materials and methods}

Preparation of carbon adsorbent

The CLP was collected from a local juice manufacturing unit in Rasipuram (Tk) and dried in the sun. Subsequently, the material was washed with boiling, deionized water five to six times for removing water soluble, extractable organics and acids. The washed material was dried in the sun for 2 days and cut into small pieces using a cutter machine. The dried raw material was subsequently digested with sufficient quantities of perchloric acid at between 300 and $350{ }^{\circ} \mathrm{C}$ to break down the fibers and then subsequently treated with concentrated sulfuric acid in a 1:2 ratio by weight and kept at $160 \pm 5{ }^{\circ} \mathrm{C}$ in an air oven for $24 \mathrm{~h}$. The carbonized material was washed with distilled water and soaked in $1 \%$ sodium bicarbonate for $24 \mathrm{~h}$ to remove any free acid. The carbon material was washed, dried and sieved to $20-50$ ASTM mesh for use in the experiments (CLPC). The
Table 1 Characteristics of the carbon

\begin{tabular}{ll}
\hline Parameter & CLPC \\
\hline Bulk density $\left(\mathrm{g} \mathrm{mL}^{-1}\right)$ & 0.51 \\
Moisture (\%) & 15.70 \\
Ash (\%) & 7.70 \\
Solubility in water (\%) & 1.74 \\
Solubility in 0.25 M HCl (\%) & 14.90 \\
pH & 5.50 \\
Decolorizing power (mg g $\left.{ }^{-1}\right)$ & 2.70 \\
Phenol number & 69.00 \\
Ion-exchange capacity $\left(\mathrm{m} \mathrm{equiv}^{-1}\right)$ & 0.47 \\
Surface area (m $\left.\mathrm{g}^{-1}\right)$ & 193 \\
Iron (\%) & 0.01 \\
Silica (\%) & $\mathrm{NIL}$ \\
Potassium (\%) & 0.08 \\
Sodium (\%) & 1.18 \\
\hline
\end{tabular}

characteristics of the carbon were determined according to ISI-877 (1977) and presented in Table 1. Raw peel at the same particle size as the carbon was also evaluated.

Preparation of the $\mathrm{Ni}(\mathrm{II})$ solutions

A stock solution of $\mathrm{Ni}(\mathrm{II})\left(100 \mathrm{mg} \mathrm{L}^{-1}\right)$ was prepared by dissolving $0.4479 \mathrm{~g}$ of $\mathrm{AR} \mathrm{NiSO}{ }_{4} \bullet 6 \mathrm{H}_{2} \mathrm{O}$ in $1000 \mathrm{~mL}$ of deionized water. Nickel (II) solutions with the desired concentrations were prepared by diluting the stock solution. The $\mathrm{pH}$ of the solution was adjusted using $0.1 \mathrm{~N} \mathrm{HCl}$ or $0.1 \mathrm{~N} \mathrm{NaOH}$ solutions. During the wastewater studies, nickel (II) wastewater was collected from M/S Metal platers in Chennai. Because the wastewater has a very high concentration of nickel $\left(2200 \mathrm{mg} \mathrm{L}^{-1}\right)$, it was diluted tenfold for the studies with CLP and CLPC.

Batch-mode studies

The batch experiments were carried out in polythene bottles ( $300 \mathrm{~mL}$ capacity) with $100 \mathrm{~mL}$ of a $10 \mathrm{mg} \mathrm{L}^{-1} \mathrm{Ni}$ (II) solution after the proper $\mathrm{pH}$ adjustments. The required amount of adsorbent was added and equilibrated for specific periods in a temperature-controlled shaker. After the equilibration period, the solutions were centrifuged and the $\mathrm{Ni}(\mathrm{II})$ concentrations were determined with an atomic absorption spectrophotometer (Elico, Model-SL163). The $\mathrm{Ni}(\mathrm{II})$ removal (\%) was calculated using the following equation (Senthil Kumar et al. 2011b; Mouni et al. 2011):

$\operatorname{Removal}(\%)=\frac{C_{0}-C_{\mathrm{e}}}{C_{0}} \times 100$

where $C_{0}$ and $C_{\mathrm{e}}$ are the initial and equilibrium $\mathrm{Ni}(\mathrm{II})$ concentrations $\left(\mathrm{mg} \mathrm{L}^{-1}\right)$, respectively. 
Effect of contact time, $\mathrm{pH}$ and adsorbent dose

The adsorption dose $(100 \mathrm{mg} / 100 \mathrm{~mL})$ was added to the $10 \mathrm{mg} \mathrm{L}^{-1} \mathrm{Ni}(\mathrm{II})$ solutions and agitated for periods ranging from 0.5 to $6 \mathrm{~h}$ at $\mathrm{pH} 5.0$. The bottles were removed at periodic intervals, and the solutions were centrifuged before the $\mathrm{Ni}$ (II) concentrations were determined. The effects of the $\mathrm{pH}$ were studied from $\mathrm{pH} 2.0-12.0$. The effects of the adsorbent dose were investigated using $10-50 \mathrm{mg} \mathrm{L}^{-1} \mathrm{Ni}(\mathrm{II})$ solutions; $50-700 \mathrm{mg} / 100 \mathrm{~mL}$ adsorbent was added and agitated for $3 \mathrm{~h}$ at $\mathrm{pH}-5.50$. The solutions were centrifuged and analyzed for $\mathrm{Ni}(\mathrm{II})$ ions. The batch experiments were repeated three times, and the results are presented as the averages. The peel and carbon were subjected to a desorption process with $\mathrm{HCl}$; the optimal concentration of acid required for desorption was $0.7 \mathrm{~N}$.

\section{Adsorption isotherms}

The adsorption isotherms were determined at different initial concentrations (10-60 $\mathrm{mg} \mathrm{L}^{-1}$ ) of $\mathrm{Ni}(\mathrm{II})$. First, $100 \mathrm{mg}$ of adsorbent was added and equilibrated for $24 \mathrm{~h}$ at different temperatures (300-320 K). The adsorption capacity for $\mathrm{Ni}(\mathrm{II})$ ions adsorbed per gram of adsorbent $\left[q_{\mathrm{e}}\right.$ $\left(\mathrm{mg} \mathrm{g}^{-1}\right)$ ] was calculated (Senthil Kumar et al. 2011b; Mouni et al. 2011; Ghasemi et al. 2014a, b):

$q_{\mathrm{e}}=\frac{C_{0}-C_{\mathrm{e}}}{M} \times V$ where $C_{0}$ and $C_{\mathrm{e}}$ are the initial and equilibrium $\mathrm{Ni}(\mathrm{II})$ concentrations $\left(\mathrm{mg} \mathrm{L}^{-1}\right), V$ is the volume of the $\mathrm{Ni}(\mathrm{II})$ solution (L), and $M$ is the mass of the adsorbent used (g).

\section{SEM-EDX and FTIR studies}

A scanning electron microscope (JOEL JSM 6360) was used to visualize the surface morphology and structure of the Ni(II) ion-loaded adsorbents. The EDX patterns were used to confirm which elements were present in the adsorbent before and after adsorbing the Ni(II) ions. Fourier transform infrared spectroscopy (FTIR) studies were carried out to identify the functional groups on the surface of the adsorbent from 400 to $4000 \mathrm{~cm}^{-1}$ while using $\mathrm{KBr}$ as the background followed by previous study Feng et al. (2009) and Onundi et al. (2010).

\section{Results and discussion}

FT-IR analysis

FTIR spectroscopy is a useful tool to study the interaction between an adsorbate and the active functional groups on the surface of the adsorbent. The chemical functional groups such as hydroxyl, carboxyl and sulfonic acid groups were identified as potential adsorption sites which are responsible for binding the metallic ions to the adsorbent. The FT-IR spectral data for CLP and CLPC before and
Fig. 1 FT-IR spectrum of CLP and CLPC before and after $\mathrm{Ni}(\mathrm{II})$ adsorption
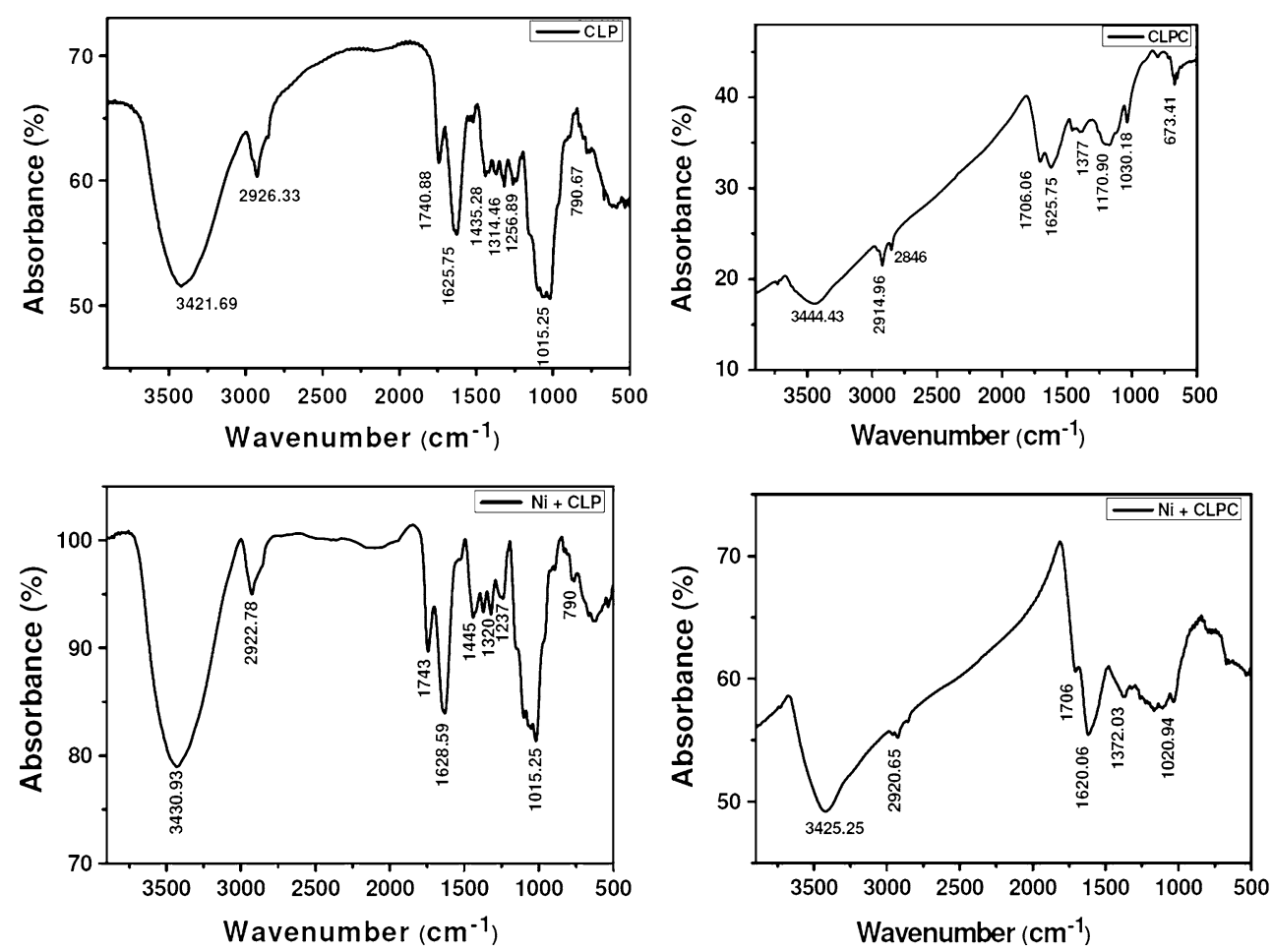
after $\mathrm{Ni}(\mathrm{II})$ adsorption are shown in Fig. 1, and the corresponding data are listed in Table 2. The spectrum shows a broad, intense peak at 3422 and $3444 \mathrm{~cm}^{-1}$, which indicates the presence of hydroxyl groups on the CLP and CLPC surface. The peak corresponds to this functional groups was altered after $\mathrm{Ni}(\mathrm{II})$ adsorption indicating their involvement in $\mathrm{Ni}$ binding. The inclusion of hydroxyl groups on the metal binding was observed by Prasad and Freitas (2000), Aydin et al. (2008). The oxygen on each hydroxyl group acts as a strong Lewis base because of the presence of its vacant double electrons, and this hydroxyl group undergoes a complex coordination with metal [Ni(II)] which is electron deficient. Further detail about the mechanism can be found elsewhere (Prasad and Freitas 2000; Aydin et al. 2008). The peaks observed at about $2915-2846 \mathrm{~cm}^{-1}$ could be assigned to aliphatic C-H groups (Malkoc and Nuhoglu 2005). The peaks at 1741 and $1706 \mathrm{~cm}^{-1}$ represent the carbonyl $(\mathrm{C}=\mathrm{O})$ stretching vibration of the carboxyl groups (Feng et al. 2009). The

Table 2 FTIR spectra absorption band/peak frequencies and corresponding possible functional groups on CLP and CLPC before and after adsorption

\begin{tabular}{|c|c|c|c|c|}
\hline \multicolumn{4}{|c|}{ Frequency $\left(\mathrm{cm}^{-1}\right)$} & \multirow{3}{*}{$\begin{array}{l}\text { Corresponding } \\
\text { functional groups }\end{array}$} \\
\hline \multicolumn{2}{|l|}{ CLP } & \multicolumn{2}{|l|}{ CLPC } & \\
\hline $\begin{array}{l}\text { Before } \\
\text { adsorption }\end{array}$ & $\begin{array}{l}\text { After } \\
\text { adsorption }\end{array}$ & $\begin{array}{l}\text { Before } \\
\text { adsorption }\end{array}$ & $\begin{array}{l}\text { After } \\
\text { adsorption }\end{array}$ & \\
\hline 3422 & 3431 & 3444 & 3425 & $\begin{array}{l}\text { Bonded }-\mathrm{OH} \\
\text { groups }\end{array}$ \\
\hline 2926 & 2923 & $\begin{array}{l}2915 \\
2846\end{array}$ & $\begin{array}{l}2921 \\
\text { Disappear }\end{array}$ & $\begin{array}{l}\text { Aliphatic } \mathrm{C}-\mathrm{H} \\
\text { groups }(\mathrm{C}-\mathrm{H} \\
\text { stretching of } \\
\mathrm{CH}_{3}, \mathrm{CH}_{2} \text { and } \\
\left.\mathrm{OCH}_{3} \text { groups }\right)\end{array}$ \\
\hline 1741 & 1743 & 1706 & 1706 & $\begin{array}{l}\mathrm{C}=\mathrm{O} \text { stretching in } \\
\text { carboxylic acid } \\
\text { group }\end{array}$ \\
\hline 1626 & 1629 & 1626 & 1620 & $\begin{array}{c}\mathrm{C}=\mathrm{C} \text { stretching } \\
\quad \text { (aromatic) }\end{array}$ \\
\hline 1435 & 1445 & - & - & $\begin{array}{l}\mathrm{C}-\mathrm{H} \text { groups in } \\
\text { the plane } \\
\text { deformation } \\
\left(\mathrm{CH}_{3}, \mathrm{CH}_{2} \text { and }\right. \\
\left.\mathrm{OCH}_{3} \text { groups }\right)\end{array}$ \\
\hline 1314 & 1320 & 1377 & 1372 & $\mathrm{COO}^{-}$stretching \\
\hline 1257 & 1237 & - & - & $\begin{array}{l}\mathrm{C}-\mathrm{O} \text { stretching in } \\
\text { carboxylic } \\
\text { acids }\end{array}$ \\
\hline - & - & 1171 & Disappear & $\begin{array}{l}\mathrm{S}=\mathrm{O} \text { stretching in } \\
\text { sulfonic acid } \\
\text { group }\end{array}$ \\
\hline 1015 & 1015 & 1030 & 1021 & $\begin{array}{l}\text { C-O stretching } \\
\text { (alcohol) }\end{array}$ \\
\hline 791 & 790 & - & - & $\begin{array}{l}\text { C-H bending } \\
\text { (aromatic) }\end{array}$ \\
\hline
\end{tabular}

peaks around $1626 \mathrm{~cm}^{-1}$ are due to the $\mathrm{C}=\mathrm{C}$ stretching that can be attributed to the presence of aromatic or benzene rings (Feng et al. 2009). The peaks observed at $1435 \mathrm{~cm}^{-1}$ in CLP are assigned to aliphatic and aromatic $(\mathrm{C}-\mathrm{H})$ groups in the plane deformation vibrations of methyl, methylene and methoxy groups (Feng et al. 2009). Carboxylate groups $\left(\mathrm{COO}^{-}\right)$are observed at a peak of 1314 and $1377 \mathrm{~cm}^{-1}$ (Terzyk 2001). The bands in the range $1300-1000 \mathrm{~cm}^{-1}$ can be assigned to the $\mathrm{C}-\mathrm{O}$ stretching vibration of carboxylic acids and alcohols (Feng et al. 2009). The peak at $1171 \mathrm{~cm}^{-1}$ in CLPC is assigned to the $\mathrm{S}=\mathrm{O}$ stretching vibration of the sulfonic acid group (Nagashanmugam and Srinivasan 2010; Kannan and Thambidurai 2008).

\section{SEM-EDX analysis}

The SEM images of the CLP and CLPC adsorbents are shown in Fig. 2a, b. The micrograph shown in Fig. 2a, b reveals the presence of a macroporous structure, which is clearly illustrated to show the fissures and holes. Comparing the SEM images of the CLP and CLPC before and after adsorption demonstrates that the metal ions are adsorbed, as confirmed with an EDX analysis. After adsorbing the metal ions, the pores on CLP and CLPC are covered. The EDX spectra of the Ni(II) ion adsorbed on CLP and CLPC show peaks for the metal ions in addition to the other cations, confirming the adsorption of $\mathrm{Ni}$ (II) ions on the surface of the adsorbent (Fig. 2c, d).

\section{Effects of the contact time on sorption}

The equilibrium time is one of the parameters for economical wastewater treatment plant applications (Kadirvelu and Namasivayam 2003). Figure 3a shows the effects of contact time on the adsorption of Ni(II) ions by CLP and CLPC. The results obtained from the Fig. 3 a reveals that the removal of $\mathrm{Ni}$ (II) ions increased rapidly over time, attaining equilibrium in $3 \mathrm{~h}$ with both CLP and CLPC. The fast adsorption at the initial stage may be due to the higher driving force making fast transfer of metal ions to the surface of adsorbent particles and the availability of the uncovered surface area and the active sites on the adsorbent (Wu et al. 2008). With further increasing time, the availability of the uncovered surface area and the remaining active sites diminishes and the decrease in the driving force make it take long time to reach equilibrium for metal ions slowly diffusing into the intra-particle pores of the adsorbent (Wu et al. 2008). Thus, the adsorption rate becomes slower. Therefore, the optimal equilibrium was $3 \mathrm{~h}$ for the subsequent experiments. Similar result in $\mathrm{Ni}(\mathrm{II})$ ions removal by activated carbon has been reported in Ref. (Kannan and Thambidurai 2008). 
(a)

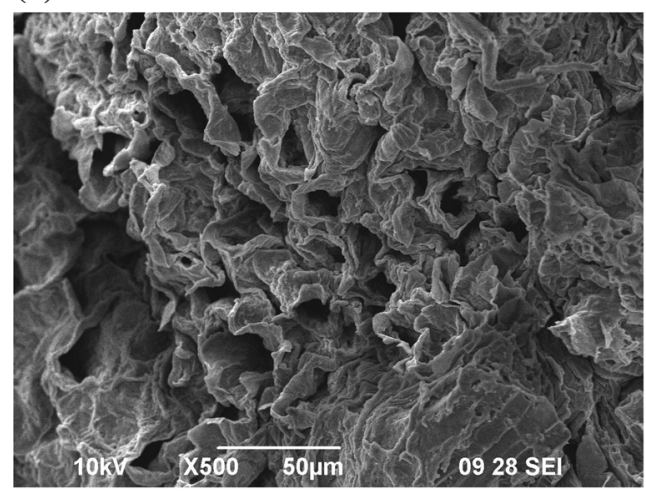

(c)

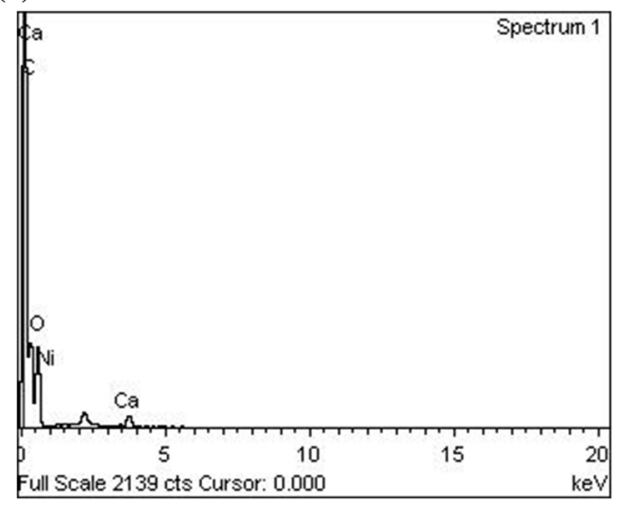

(b)

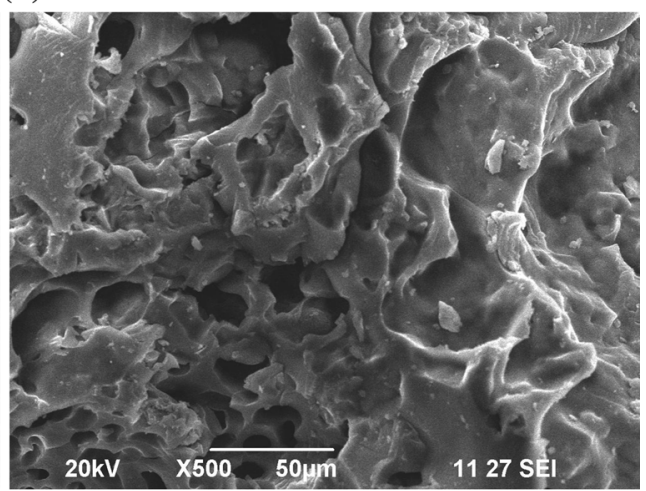

(d)

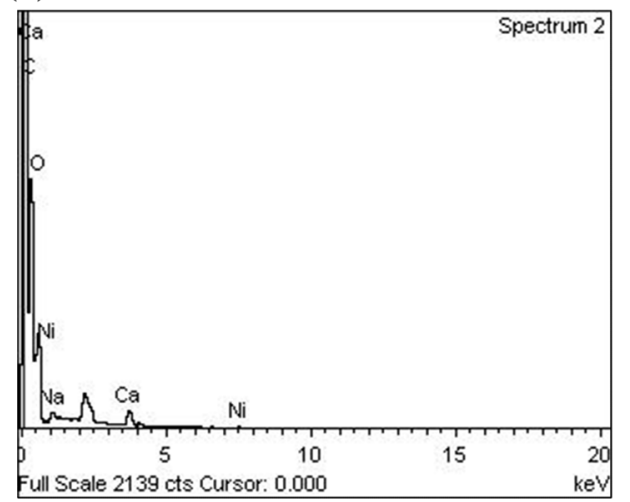

Fig. 2 a, b SEM image of CLP and CLPC; c, d EDX patterns for CLP and CLPC for after Ni(II) adsorption

(a)

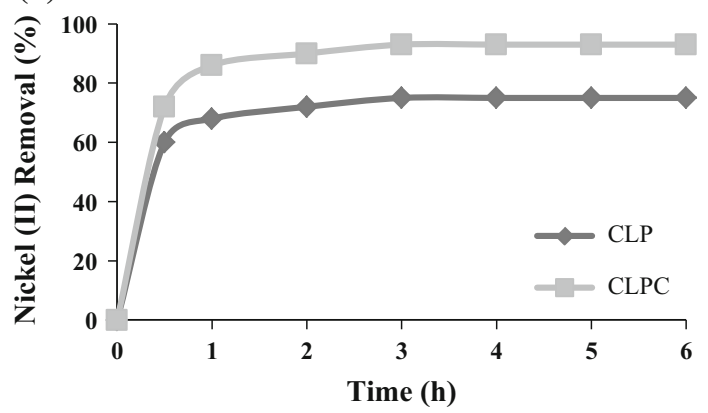

(b)

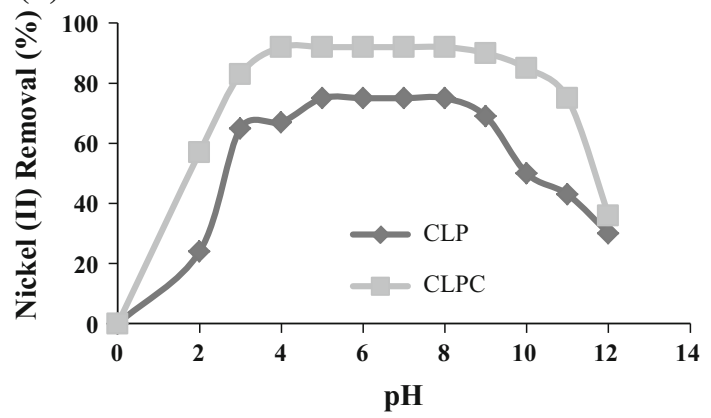

Fig. 3 a, b Effects of contact time and $\mathrm{pH}$ on the $\mathrm{Ni}(\mathrm{II})$ adsorption onto CLP and CLPC $\left(C_{\mathrm{o}}=10 \mathrm{mg} \mathrm{L}^{-1}\right.$; adsorbent dose $=100 \mathrm{mg} /$ $100 \mathrm{~mL} ; \mathrm{Temp}=300( \pm 2) \mathrm{K})$
Effects of the solution $\mathrm{pH}$ on sorption

The solution $\mathrm{pH}$ is an important controlling parameter for the removal of heavy metals from aqueous solution. The $\mathrm{pH}$ value affects the surface charge of the adsorbent, the degree of ionization and speciation of the adsorbate during the adsorption process (Ugurlu et al. 2009). Thus, the effect of $\mathrm{H}^{+}$ion concentration in the aqueous solutions on the percentage removal of $\mathrm{Ni}(\mathrm{II})$ ions was studied at different $\mathrm{pH}$ ranging from 2.0 to 12.0 . Fig. $3 \mathrm{~b}$ shows that the adsorption increases when the $\mathrm{pH}$ is increased, attaining the maximum removal $70( \pm 0.3) \%$ at $\mathrm{pH}$ of $5.0-8.0$ for CLP and $92( \pm 0.4) \%$ over the $\mathrm{pH}$ range at $4.0-8.0$ for CLPC, respectively. The $\mathrm{pH}$ dependency of adsorption efficiency could be explained by the functional groups involved in metal uptake and metal chemistry. The FT-IR spectroscopic analysis shows that the CLP and CLPC have a variety of functional groups such as hydroxyl, carboxyl and sulfonic acid groups which are involved in almost all the potential binding mechanisms. Moreover, depending on the solution $\mathrm{pH}$, the functional groups participate in metal ion bindings. At low $\mathrm{pH}$ values, $\mathrm{H}^{+}$ions occupy most of the adsorption sites on the CLP and CLPC surface and less nickel could be sorbed because of electrostatic repulsion with $\mathrm{H}^{+}$ions on CLP and CLPC surface. When the $\mathrm{pH}$ is 
increased, more negatively charged surface became available which facilitated greater $\mathrm{Ni}$ (II) uptake on the surface of CLP and CLPC. The decrease in adsorption efficiency at higher $\mathrm{pH}(>8.0)$ was due to the formation of soluble hydroxylated complexes of nickel ions and their competition with the active sites; as a result, the retention would decrease again (Lee and Lee 2005). The results obtained from the present study are in accordance with the earlier study related to the effect of solution $\mathrm{pH}$ on metal adsorption process by low-cost adsorbent (Ugurlu et al. 2009; Prasad and Abdullah 2009; Shroff and Vaidya 2011).

The mechanism of $\mathrm{Ni}(\mathrm{II})$ removal may also be explained based on ion-exchange model. A pure carbon surface is considered to be nonpolar, but in actual practice some carbon-oxygen complexes $\left(\mathrm{C}_{\mathrm{X}} \mathrm{O}, \mathrm{CO}_{\mathrm{X}}\right.$ and $\left.\mathrm{C}_{\mathrm{X}} \mathrm{O}_{2}\right)$ are usually present, which render the surface slightly polar (Michelson et al. 1975). The surface oxygen complexes hydrolyse water molecules as shown below;

$$
\begin{aligned}
& \mathrm{C}_{\mathrm{X}} \mathrm{O}+2 \mathrm{H}_{2} \mathrm{O} \rightarrow \mathrm{C}_{\mathrm{X}} \mathrm{OH}_{2}^{2+}+2 \mathrm{OH}^{-} \\
& \mathrm{CO}_{\mathrm{X}}+\mathrm{x} \mathrm{H}_{2} \mathrm{O} \rightarrow \mathrm{C}(\mathrm{OH})_{\mathrm{X}}^{+}+\mathrm{x} \mathrm{OH}^{-} \\
& \mathrm{C}_{\mathrm{X}} \mathrm{O}_{2}+\mathrm{H}_{2} \mathrm{O} \rightarrow \mathrm{C}_{\mathrm{X}} \mathrm{O}^{2+}+2 \mathrm{OH}^{-}
\end{aligned}
$$

Since the CLPC is prepared upon treatment with $\mathrm{H}_{2} \mathrm{SO}_{4}$ followed by $\mathrm{NaHCO}_{3}$ treatment, groups such as $\mathrm{C}_{\mathrm{X}} \mathrm{O} \mathrm{Na}{ }^{+}$, $\mathrm{C}_{\mathrm{X}} \mathrm{O} \mathrm{Na}{ }_{2}^{2+}, \mathrm{C}_{\mathrm{X}} \mathrm{SO}_{3} \mathrm{H}$ and $\mathrm{C}_{\mathrm{X}} \mathrm{SO}_{3} \mathrm{Na}$ are also assumed to be present. Hence, it is expected that $\mathrm{Na}^{+}$may be exchanged with $\mathrm{Ni}(\mathrm{II})$ and soluble complexes of $\mathrm{Ni}(\mathrm{II})$ as follows:

$$
\begin{aligned}
& 2 \mathrm{C}_{\mathrm{X}} \mathrm{OH}^{+}+\mathrm{Ni}^{2+} \rightarrow\left(\mathrm{C}_{\mathrm{X}} \mathrm{O}\right)_{2} \mathrm{Ni}^{2+}+2 \mathrm{H}^{+} \\
& \mathrm{C}_{\mathrm{X}} \mathrm{OH}_{2}^{2+}+\mathrm{Ni}^{2+} \rightarrow \mathrm{C}_{\mathrm{X}} \mathrm{ONi}^{2+}+2 \mathrm{H}^{+} \\
& 2 \mathrm{C}_{\mathrm{X}} \mathrm{ONa}^{+}+\mathrm{Ni}^{2+} \rightarrow\left(\mathrm{C}_{\mathrm{X}} \mathrm{O}\right)_{2} \mathrm{Ni}^{2+}+2 \mathrm{Na}^{+} \\
& \mathrm{C}_{\mathrm{X}} \mathrm{ONa}_{2}^{2+}+\mathrm{Ni}^{2+} \rightarrow \mathrm{C}_{\mathrm{X}} \mathrm{ONi}^{2+}+2 \mathrm{Na}^{+} \\
& 2 \mathrm{C}_{\mathrm{X}} \mathrm{SO}_{3} \mathrm{H}+\mathrm{Ni}^{2+} \rightarrow\left(\mathrm{C}_{\mathrm{X}} \mathrm{SO}_{3}\right)_{2} \mathrm{Ni}+2 \mathrm{H}^{+} \\
& 2 \mathrm{C}_{\mathrm{X}} \mathrm{SO}_{3} \mathrm{Na}+\mathrm{Ni}^{2+} \rightarrow\left(\mathrm{C}_{\mathrm{X}} \mathrm{SO}_{3}\right)_{2} \mathrm{Ni}+2 \mathrm{Na}^{+}
\end{aligned}
$$

The above mechanism was verified quantitatively by the release of sodium ions in the treated water due to the adsorption of nickel ions.

\section{Effects of the adsorbent dose}

The adsorbent dose is an important parameter because it determines the capacity of an adsorbent for a given initial concentration of metal ions (Mousavi and Seyedi 2011). The number of available sites and exchanging ions for the adsorption depends upon the amount of adsorbent in the adsorption process. The effect of the adsorbent dose on the $\mathrm{Ni}(\mathrm{II})$ removal over different initial $\mathrm{Ni}$ (II) concentrations is shown in Fig. 4a, b. Initially, the removal increases very sharply when increasing the adsorbent dose at an optimal $\mathrm{pH}$ but beyond $500 \mathrm{mg} / 100 \mathrm{~mL}$ for CLP and $200 \mathrm{mg} / 100 \mathrm{~mL}$
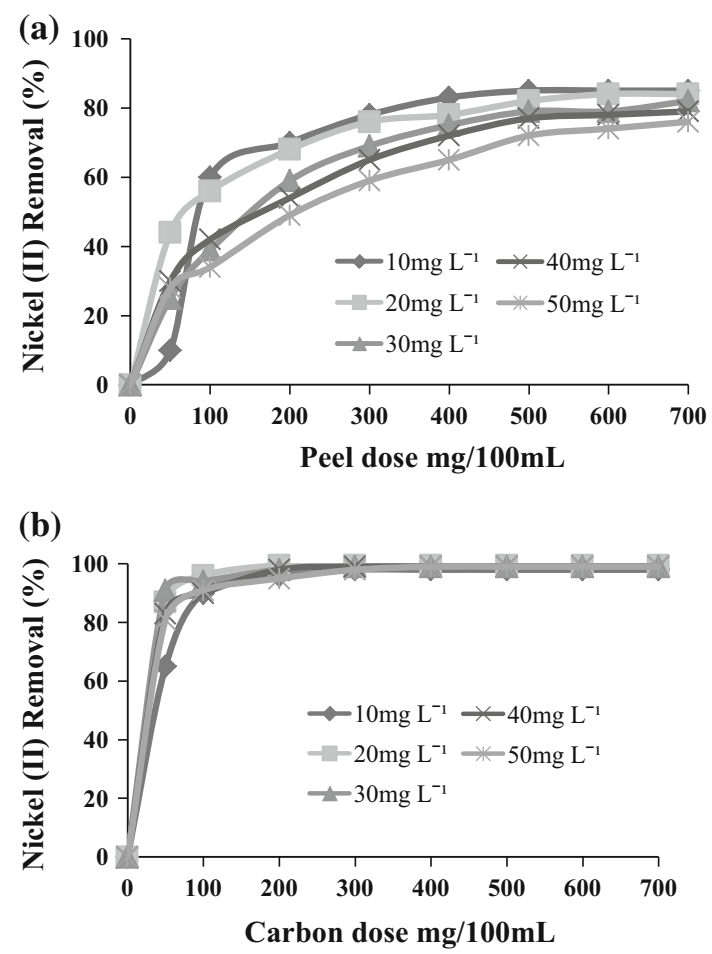

Fig. 4 a, b Effects of the adsorbent dose on the Ni(II) adsorption onto CLP and CLPC $\left(C_{\mathrm{o}}=10-50 \mathrm{mg} \mathrm{L}^{-1}\right.$; adsorbent dose $=$ $50-700 \mathrm{mg} ; \mathrm{pH}=5.5$; agitation time $=3 \mathrm{~h}$ )

for CLPC; the percentage removal reaches almost a constant value, and this may be due to reduction in concentration gradient. The maximum adsorption efficiency of $\mathrm{Ni}$ (II) ions onto CLP and CLPC was found to be $85( \pm 0.5)$ and 99 $( \pm 0.4) \%$ at an adsorbent dose of 500 and $200 \mathrm{mg}$, respectively. The increase in removal efficiency of $\mathrm{Ni}(\mathrm{II})$ ions can be attributed to the increase in surface area resulting from the increase in adsorbent mass or greater availability of the exchangeable sites for adsorption. Same trend was reported by (Mouni et al. 2011; Mousavi and Seyedi 2011; Ghasemi et al. 2014a, b). The data clearly indicate that CLPC is nearly 2.5 times more effective than CLP with respect to the adsorbent dose; this difference occurs because the ion-exchange capacity exhibited by CLPC is moderate compared with that of CLP. Figure $4 \mathrm{~b}$ shows that the optimal dose of CLPC remains constant for various concentrations of $\mathrm{Ni}$ (II) removal. Figure $4 \mathrm{a}$ reveals that the optimal dose of CLP varied as the $\mathrm{Ni}(\mathrm{II})$ concentration increased. These observations explain that highly non-uniform distributions of adsorption sites are available on CLP.

\section{Adsorption isotherms}

A good description of the equilibrium separation between the two phases is required for successful representations of the dynamic adsorptive separation between the solute and the solution onto an adsorbent. To determine the adsorption 
capacity for nickel (II) on CLP and CLPC, adsorption data were applied to the Freundlich, Langmuir, Temkin and Dubinin-Radushkevich isotherm equations at different temperatures for regression analyses.

The Freundlich isotherm assumes that a heterogeneous surface is present with a non-uniform distribution of the heat of sorption. This model can be linearly expressed as follows (Shrestha et al. 2013b):

$\log q_{\mathrm{e}}=\log K_{\mathrm{F}}+(1 / n) \log C_{\mathrm{e}}$

where $K_{\mathrm{F}}\left(\mathrm{mg} \mathrm{g}^{-1}\right)$ and $1 / n$ are the Freundlich constants related to sorption capacity and intensity, respectively. When $1 / n$ is less than 1 , the adsorption is favorable (Bouguerra et al. 2007). The Freundlich constants can be obtained by plotting $\log q_{\mathrm{e}}$ versus $\log C_{\mathrm{e}}$.

The Langmuir (Langmuir 1918) isotherm assumes that adsorption occurs at specific homogenous sites within the adsorbent. The equation is as follows:

$\frac{C_{\mathrm{e}}}{q_{\mathrm{e}}}=\frac{1}{Q_{0} b}+\frac{1}{Q_{0}} c_{\mathrm{e}}$

where $C_{\mathrm{e}}\left(\mathrm{mg} \mathrm{L}^{-1}\right)$ is the equilibrium concentration of the adsorbate, $q_{\mathrm{e}}\left(\mathrm{mg} \mathrm{g}^{-1}\right)$ is the amount of adsorbate per unit mass of adsorbent, $b\left(\mathrm{~L} \mathrm{mg}^{-1}\right)$ is the Langmuir adsorption constant, and $Q_{0}\left(\mathrm{mg} \mathrm{g}^{-1}\right)$ is maximum adsorption. To determine whether the adsorption is favorable, a dimensionless constant separation factor or equilibrium parameter $R_{\mathrm{L}}$ is defined based on the following equation (Weber and Chakkravorti 1974):

$R_{\mathrm{L}}=\frac{1}{1+b C_{0}}$

where $b\left(\mathrm{~L} \mathrm{mg}^{-1}\right)$ is the Langmuir isotherm constant, $C_{0}$ ( $\mathrm{mg} \mathrm{L}^{-1}$ ) is the initial $\mathrm{Ni}(\mathrm{II})$ concentration, and the $R_{\mathrm{L}}$ values indicate whether the type of isotherm is favorable $\left(0<R_{\mathrm{L}}<1\right)$, unfavorable $\left(R_{\mathrm{L}}>1\right)$, linear $\left(R_{\mathrm{L}}=1\right)$, or irreversible $\left(R_{\mathrm{L}}=0\right)$ (Senturk et al. 2010). The Langmuir constants can be obtained by plotting $C_{\mathrm{e}} / q_{\mathrm{e}}$ versus $C_{\mathrm{e}}$.

Temkin considered the effects of some indirect adsorbent-adsorbate interactions on the adsorption isotherms, suggesting that these interactions cause the heat of adsorption for all of the molecules in the layer to decrease linearly with the coverage. The Temkin isotherm has been applied in the following form (Mousavi and Seyedi 2011):

$q_{\mathrm{e}}=B_{\mathrm{T}} \ln K_{\mathrm{T}}+B_{\mathrm{T}} \ln C_{\mathrm{e}}$

where $B_{\mathrm{T}}=R T / b_{\mathrm{T}}, T$ (Kelvin) is the absolute temperature, $R$ is the universal gas constant $\left(8.314 \mathrm{~J} \mathrm{~mol}^{-1} \mathrm{~K}^{-1}\right), K_{\mathrm{T}}$ $\left(\mathrm{L} \mathrm{mg}^{-1}\right)$ is the equilibrium binding constant that corresponds to the maximum binding energy, $b_{\mathrm{T}}$ is the variation in the adsorption energy $\left(\mathrm{kJ} \mathrm{mol}^{-1}\right)$, and $B_{\mathrm{T}}$ is a Temkin constant related to the heat of adsorption $\left(\mathrm{kJ} \mathrm{mol}^{-1}\right)$. The Temkin constants can be derived by plotting $q_{\mathrm{e}}$ versus $\ln$
$C_{\mathrm{e}}$. Previous reports (Ho et al. 1996) indicated that the typical range for the binding energy during ion-exchange mechanisms is $8-16 \mathrm{~kJ} \mathrm{~mol}^{-1}$.

Dubinin-Radushkevich (Dubinin 1960) isotherm is generally applied to express the adsorption mechanism with a Gaussian energy distribution onto a heterogeneous surface. The model has often successfully fitted high solute activities and intermediate range of concentrations data well.

$q_{\mathrm{e}}=\left(q_{\mathrm{s}}\right) \exp \left(-K_{\mathrm{ad}} \varepsilon^{2}\right)$

$\ln q_{\mathrm{e}}=\ln q_{\mathrm{s}}-\left(K_{\mathrm{ad}} \varepsilon^{2}\right)$

where $q_{\mathrm{e}}, q_{\mathrm{s}}, K_{\mathrm{ad}}, \varepsilon$ are $q_{\mathrm{e}}=$ amount of adsorbate in the at equilibrium $\left(\mathrm{mg} \mathrm{g}^{-1}\right), q_{\mathrm{s}}=$ theoretical isotherm saturation capacity $\left(\mathrm{mg} \mathrm{g}^{-1}\right), K_{\text {ad }}=$ Dubinin-Radushkevich isotherm constant $\left(\mathrm{mol}^{2} \mathrm{~kJ}^{-2}\right)$ related to sorption energy and $\varepsilon=$ Dubinin-Radushkevich isotherm constant. The approach was usually applied to distinguish the physical and chemical adsorption of metal ions with its mean free energy; $E$ per molecule of adsorbate can be computed by the relationship (Dubinin 1960):

$E=\left[\frac{1}{\sqrt{2 K_{\mathrm{ad}}}}\right]$

where $K_{\text {ad }}$ is denoted as the isotherm constant. Meanwhile, the parameter $\varepsilon$ can be calculated as:

$\varepsilon=R T \ln \left[1+\frac{1}{C_{\mathrm{e}}}\right]$

where $R, \quad T$ and $C_{\mathrm{e}}$ represent the gas constant (8.314 $\mathrm{J} \mathrm{mol}^{-1} \mathrm{~K}^{-1}$ ), absolute temperature (Kelvin) and adsorbate equilibrium concentration $\left(\mathrm{mg} \mathrm{L}^{-1}\right)$, respectively. The Dubinin-Radushkevich isotherm constants, theoretical isotherm capacity $\left(q_{\mathrm{s}}\right)$ and sorption energy $\left(K_{\mathrm{ad}}\right)$ are calculated from the plot of $\ln q_{\mathrm{e}}$ versus $\varepsilon^{2}$. The magnitude of $E$ is used to determine the type of adsorption mechanism. When one mole of ions is transferred to the adsorbent surface, its value is less than $8 \mathrm{~kJ} \mathrm{~mol}^{-1}$ which indicates the physical adsorption (Kundu and Gupta 2006). If the value of $E$ is between 8 and $16 \mathrm{~kJ} \mathrm{~mol}^{-1}$, it indicates the adsorption process follows ion exchange (Senthil kumar et al. 2011a) and when its value in the range of $20-40 \mathrm{~kJ} \mathrm{~mol}^{-1}$, it indicates chemisorptions (Chen et al. 2010).

The linearized Freundlich, Langmuir, Temkin and Dubinin-Radushkevich adsorption isotherms for the $\mathrm{Ni}$ (II) ions were obtained at 300,310 and $320 \mathrm{~K}$, as shown in Fig. $5 \mathrm{a}-\mathrm{h}$. The isotherm constants and correlation coefficients $\left(R^{2}\right)$ are summarized in Table 3. Table 3 shows that CLP and CLPC fit quite into the Lamgmuir model at different temperatures based on the $R^{2}$ value. Furthermore, the $R_{\mathrm{L}}$ values for the Langmuir isotherm fall between 0 and 1 


\section{(a) CLP}

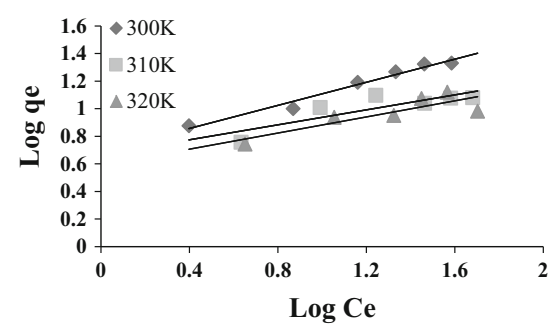

(d) CLPC

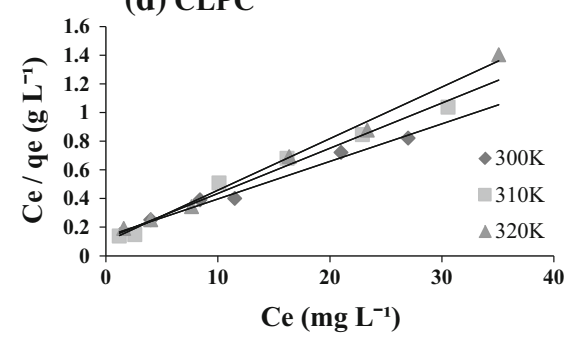

(g) CLP

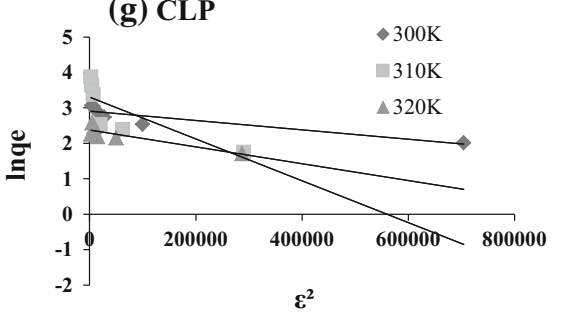

(b) CLPC

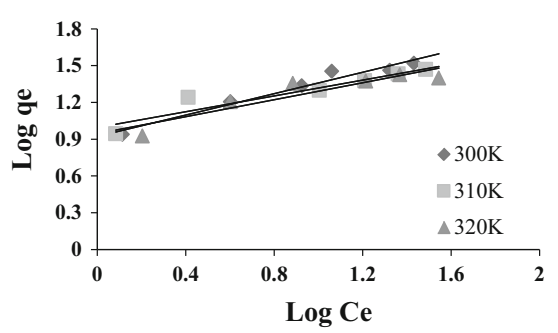

(e) CLP

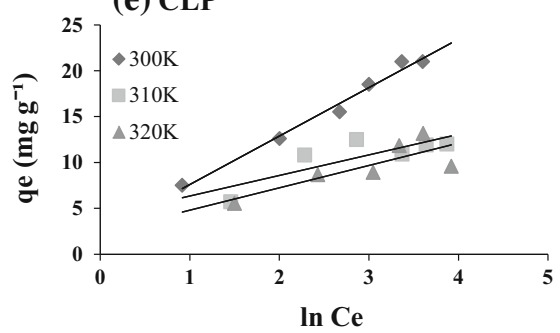

(h) CLPC

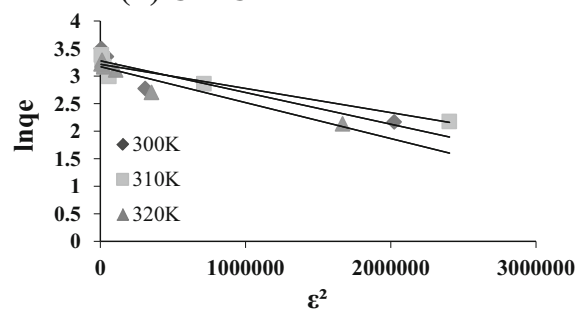

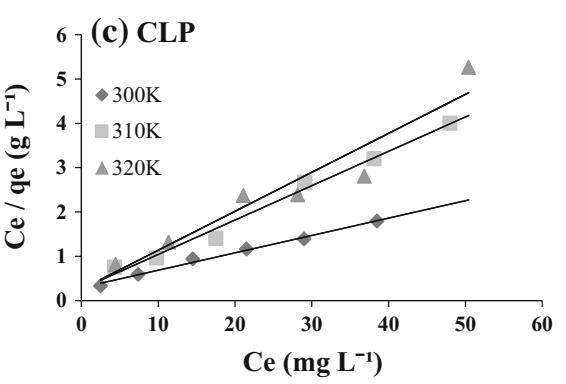

(f) CLPC

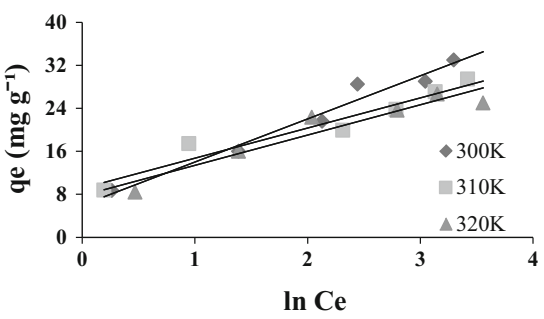

Fig. 5 a-h Adsorption isotherms for the Ni(II) ions adsorbed on CLP and CLPC: Freundlich-(a, b); Langmuir-(c, d); Temkin-(e, f); Dubinin-Radushkevich— $(\mathbf{g}, \mathbf{h})\left(C_{\mathrm{o}}=10-60 \mathrm{mg} \mathrm{L}^{-1}\right.$; agitation time-24 h; adsorbent dose $\left.=100 \mathrm{mg} / 100 \mathrm{~mL} ; \mathrm{pH}=5.5\right)$

at different temperatures (Table 3), indicating a favorable adsorption process. Lower $R_{\mathrm{L}}$ values at higher initial $\mathrm{Ni}$ (II) concentrations and lower temperature showed that adsorption was more favorable at higher concentration and lower temperature. Therefore, the active sites are distributed homogeneously on the adsorbent surface. The maximum adsorption capacity $\left(Q_{0}\right)$ decreases when increasing the temperature, revealing an exothermic process. According to the Langmuir equation, the maximum adsorption capacity $\left(Q_{0}\right)$ of $\mathrm{Ni}(\mathrm{II})$ on CLPC was $38.46 \mathrm{mg} \mathrm{g}^{-1}$ at $300 \mathrm{~K}$, which is significantly higher than that for CLP $\left(Q_{0}=25.64 \mathrm{mg} \mathrm{g}^{-1}\right)$. The ratio of the $Q_{0}$ values for CLPC and CLP is 1.5. The low $b_{\mathrm{T}}$ and $E$ values obtained in the Temkin and Dubinin-Radushkevich study (Table 3) indicate that a weak interaction exists between the sorbate and sorbent. Based on the characteristics of the carbon, an ion-exchange mechanism may also be operating in CLPC during the nickel (II) removal process.

The maximum adsorption capacity $\left(Q_{0}\right)$ of CLPC is compared with that of other adsorbents reported in the literature in Table 4 . The high adsorption capacity of CLPC reveals that it should be promising adsorbent for removing $\mathrm{Ni}(\mathrm{II})$ from aqueous system.
Thermodynamics studies

The thermodynamic considerations can be investigated through the Gibbs free energy, enthalpy and entropy. The change in the standard free energy $\left(\Delta G^{\circ}\right)$ is calculated using the following relationship:

$\Delta G^{\circ}=-R T \ln K$

where $K\left(\mathrm{~L} \mathrm{~g}^{-1}\right)$ is an equilibrium constant obtained by multiplying the Langmuir constants $Q_{\mathrm{o}}$ and $b$ (Aksu and Isoglu 2005), $T$ is the absolute temperature (Kelvin), and $R$ is the gas constant $\left(8.314 \mathrm{~J} \mathrm{~mol}^{-1} \mathrm{~K}^{-1}\right)$. The relationship between the changes in the Gibbs free energy, entropy $\left(\Delta S^{\circ}\right)$ and enthalpy $\left(\Delta H^{\circ}\right)$ can be expressed as follows:

$\Delta G^{\circ}=\Delta H^{\circ}-T \Delta S^{\circ}$

$\Delta S^{\circ}$ and $\Delta H^{\circ}$ were obtained from the slope and intercept after plotting $\Delta G^{\circ}$ versus $T$ (Fig. 6).

The calculated thermodynamic parameters for the CLPand CLPC-mediated adsorption of nickel are given in Table 3. Generally, the change in the free energy for physisorption is between -20 and $0 \mathrm{~kJ} \mathrm{~mol}^{-1}$. However, 
Table 3 Isothermal and Thermodynamic parameters for Ni(II) removal from aqueous solutions

\begin{tabular}{|c|c|c|c|c|c|c|c|}
\hline \multirow[t]{3}{*}{ Isotherm models and Thermodynamic } & \multirow[t]{3}{*}{ Parameters } & \multicolumn{6}{|c|}{ Temperature $(\mathrm{K})$} \\
\hline & & \multicolumn{3}{|l|}{ CLP } & \multicolumn{3}{|l|}{ CLPC } \\
\hline & & $300 \mathrm{~K}$ & $310 \mathrm{~K}$ & $320 \mathrm{~K}$ & $300 \mathrm{~K}$ & $310 \mathrm{~K}$ & $320 \mathrm{~K}$ \\
\hline \multirow[t]{3}{*}{ Freundlich } & $K_{\mathrm{F}}\left(\mathrm{mg} \mathrm{g}^{-1}\right)$ & 5.430 & 4.613 & 3.881 & 9.885 & 8.790 & 8.340 \\
\hline & $1 / n$ & 0.418 & 0.271 & 0.290 & 0.443 & 0.322 & 0.346 \\
\hline & $R^{2}$ & 0.972 & 0.709 & 0.728 & 0.964 & 0.893 & 0.842 \\
\hline \multirow[t]{4}{*}{ Langmuir } & $Q_{\mathrm{o}}\left(\mathrm{mg} \mathrm{g}^{-1}\right)$ & 25.64 & 12.99 & 11.36 & 38.46 & 32.26 & 27.78 \\
\hline & $b\left(\mathrm{~L} \mathrm{mg}^{-1}\right)$ & 0.292 & 0.265 & 0.255 & 0.135 & 0.120 & 0.097 \\
\hline & $R^{2}$ & 0.991 & 0.988 & 0.914 & 0.986 & 0.981 & 0.992 \\
\hline & $R_{\mathrm{L}}$ & $0.26-0.05$ & $0.27-0.06$ & $0.28-0.06$ & $0.43-0.11$ & $0.45-0.12$ & $0.52-0.15$ \\
\hline \multirow[t]{3}{*}{ Temkin } & $K_{\mathrm{T}}\left(\mathrm{L} \mathrm{mg}^{-1}\right)$ & 1.528 & 6.293 & 2.620 & 2.116 & 5.057 & 3.985 \\
\hline & $b_{\mathrm{T}}\left(\mathrm{kJ} \mathrm{mol}^{-1}\right)$ & 0.471 & 0.834 & 1.091 & 0.311 & 0.559 & 0.473 \\
\hline & $R^{2}$ & 0.984 & 0.664 & 0.652 & 0.965 & 0.935 & 0.902 \\
\hline \multirow[t]{4}{*}{ Dubinin-Radushkevich } & $q_{\mathrm{s}}\left(\mathrm{mg} \mathrm{g}^{-1}\right)$ & 18.32 & 27.19 & 10.72 & 26.42 & 24.90 & 24.07 \\
\hline & $k_{\mathrm{id}}\left(\mathrm{mol}^{2} \mathrm{~kJ}^{-2}\right)$ & $1 \times 10^{-6}$ & $6 \times 10^{-6}$ & $2 \times 10^{-6}$ & $6 \times 10^{-7}$ & $4 \times 10^{-7}$ & $7 \times 10^{-7}$ \\
\hline & $E\left(\mathrm{~kJ} \mathrm{~mol}^{-1}\right)$ & 0.707 & 0.290 & 0.500 & 0.913 & 1.119 & 0.845 \\
\hline & $R^{2}$ & 0.841 & 0.640 & 0.773 & 0.837 & 0.917 & 0.921 \\
\hline \multirow[t]{3}{*}{ Thermodynamic } & $\Delta G^{\circ}\left(\mathrm{kJ} \mathrm{mol}^{-1}\right)$ & -5.021 & -3.189 & -2.831 & -4.109 & -3.489 & -2.637 \\
\hline & $\Delta H^{\circ}\left(\mathrm{kJ} \mathrm{mol}^{-1}\right)$ & -37.635 & & & -26.218 & & \\
\hline & $\Delta S^{\circ}\left(\mathrm{kJ} \mathrm{mol}^{-1} \mathrm{~K}^{-1}\right)$ & -0.110 & & & -0.074 & & \\
\hline
\end{tabular}

Table 4 Monolayer adsorption capacities in the literature for Ni(II) adsorption

\begin{tabular}{lc}
\hline Adsorbent & $\begin{array}{l}\mathrm{Q}_{0} \\
\left(\mathrm{mg} \mathrm{g}^{-1}\right)\end{array}$ \\
\hline Cashew nut shell (Senthil Kumar et al. 2011b) & 18.87 \\
Palm shell (Onundi et al. 2010) & 0.13 \\
Ceiba pentandra hulls (Venkata Ramana et al. 2012) & 34.34 \\
Almond husk activated with $\mathrm{H}_{2} \mathrm{SO}_{4}$ (Hasar 2003) & 37.18 \\
Walnut shell waste (Wang et al. 2010) & 15.34 \\
Cajanus cajan L milsp seed shell activated carbon & 25.75 \\
$\quad$ Thamilarasu et al. 2011) & 25.00 \\
Cottonseed cake (Ozbay 2009) & 31.15 \\
Ricinus communis pericarp (Madhavakrishnan et al. & \\
2008) & 35.30 \\
Watermelon rind (Lakshmipathy and Sarada 2013) & 28.25 \\
Lapsi (Choerospondias axillaris) seed stone (Shrestha & \\
$\quad$ et al. 2013a) & 5.58 \\
Carica papaya seed (Chithra et al. 2014) & 25.64 \\
CLP (the present study) & 38.46 \\
CLPC (the present study)
\end{tabular}

chemisorption ranges -80 to $-400 \mathrm{~kJ} \mathrm{~mol}^{-1}$ (Reddad et al. 2002). The overall change in the free energy during the adsorption process was negative for the experimental temperature ranges (Table 3). The data correspond to a spontaneous physical process of nickel adsorption, and the system does not gain energy from an external source. The
$\Delta G^{\circ}$ value is more negative when decreasing the temperature, suggesting that lower temperatures favor the adsorption. The negative $\Delta H^{\circ}$ value implies that the adsorption phenomenon is exothermic and explains the decrease in $\mathrm{Ni}$ (II) ion adsorption efficiency that was observed as the temperature increased. The negative $\Delta S^{\circ}$ value suggests that the process is driven by enthalpy.

$\mathrm{Ni}(\mathrm{II})$ removal from electroplating wastewater and Regeneration studies

Batch experiments with nickel electroplating wastewater have been carried out to elucidate the applicability of both sorbents under batch-mode operations. The characteristics of nickel plating wastewater are shown in Table 5. As the wastewater has a very high concentration of nickel (2200 $\mathrm{mg} \mathrm{L}^{-1}$ ), it was diluted to ten times to conduct experiments with CLP and CLPC, earlier studies followed by Kannan and Thambidurai (2008), Feng et al. (2009).When removing $\mathrm{Ni}(\mathrm{II})$ from wastewater containing $220 \mathrm{mg}$ of $\mathrm{Ni}(\mathrm{II}) / 100 \mathrm{~mL}$, the optimum CLP and CLPC doses were 1000 and $400 \mathrm{mg}$ reaching maximum removals of 86 $( \pm 0.6) \%$ and $98( \pm 0.5) \%$, respectively. Therefore, CLPC is more effective than CLP when treating nickel plating wastewater due to the moderate ion exchange observed with CLPC compared to CLP.

To determine the applicability of the adsorbent over repeated uses, $0.7 \mathrm{~N} \mathrm{HCl}$ was used to regenerate the peel 


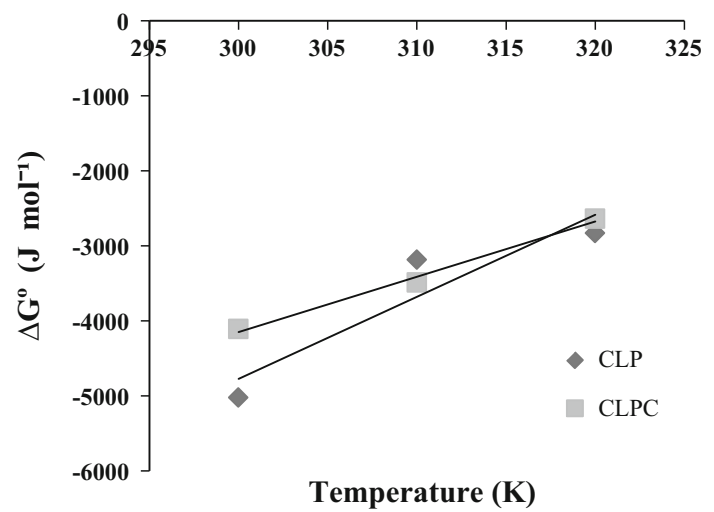

Fig. 6 Changes in the Gibbs free energy versus the temperature

Table 5 Characteristics of nickel plating industry wastewater

\begin{tabular}{lr}
\hline $\mathrm{pH}$ & 1.90 \\
Conductivity $\left(\mathrm{ms} \mathrm{cm}^{-1}\right)$ & 14.35 \\
Total solid $\left(\mathrm{mg} \mathrm{L}^{-1}\right)$ & 6579.00 \\
Turbidity $(\mathrm{NTU})$ & 20.00 \\
Chloride $\left(\mathrm{mg} \mathrm{L}^{-1}\right)$ & 789.00 \\
Sulfate $\left(\mathrm{mg} \mathrm{L}^{-1}\right)$ & 2036.00 \\
$\mathrm{COD}\left(\mathrm{mg} \mathrm{L}^{-1}\right)$ & 48.00 \\
Iron $\left(\mathrm{mg} \mathrm{L}^{-1}\right)$ & 47.50 \\
Nickel $\left(\mathrm{mg} \mathrm{L}^{-}\right)^{1}$ & 2200.00 \\
Sodium $\left(\mathrm{mg} \mathrm{L}^{-1}\right)$ & 466.00 \\
Calcium $\left(\mathrm{mg} \mathrm{L}^{-1}\right)$ & 89.00 \\
Magnesium $\left(\mathrm{mg} \mathrm{L}^{-1}\right)$ & 168.00 \\
\hline
\end{tabular}

and carbon over five cycles of operation. A slight increase in the sorption of $\mathrm{Ni}(\mathrm{II})$ could be observed after each and every cycle with CLPC, improving the recovery of Ni(II) ions. This increase in the sorption (98.0-99.9 \%) may occur because additional surface active sites present on the sorbent surface open after repeated regeneration cycles (Rao and Ikram 2011). However, the recovery of Ni(II) decreased in CLPC from 80.27 to $60.73 \%$ during fifth cycle because the $\mathrm{Ni}$ (II) ions were strongly bound to the new opening sites. For CLP, both the adsorption and desorption values decreased rapidly. Therefore, CLPC has a greater potential for repeated uses and the recovery of $\mathrm{Ni}(\mathrm{II})$ ions. The attrition losses were also calculated at the end of the fifth cycle. The CLPC showed $3.0 \%$ losses on average, while CLP showed 5-6\% losses at the end of the cycle during batch-mode operations.

\section{Conclusion}

Citrus limettioides peel and its carbon derivative can be used to remove $85-99 \%$ of the $\mathrm{Ni}$ (II) from aqueous solutions. The presence of hydroxyl, carboxylic and sulfonic acid groups in CLPC is confirmed by FT-IR spectroscopy, imparting ion-exchange properties to the CLPC. The equilibrium data agreed with the Langmuir isotherm, and the adsorption capacity $\left(Q_{\mathrm{o}}\right)$ of CLPC is 1.5 times larger than that of CLP. The thermodynamic parameters indicate that the adsorption process is spontaneous, feasible and exothermic. The experiments with nickel (II) electroplating wastewater revealed that CLPC is more effective than CLP. The CLPC was tested for five adsorption and regeneration cycles for the removal of $\mathrm{Ni}(\mathrm{II})$ ions from wastewater, revealing lesser tendency toward attrition when compared to CLP. Therefore, the present studies reveal that the carbon derived from CLP is a very effective and inexpensive adsorbent for removing $\mathrm{Ni}(\mathrm{II})$ from aqueous systems.

Acknowledgments Authors thank the Chairman, Department of Chemistry, Gnanamani College of Technology, Anna University, Chennai (India), for providing research facilities.

\section{References}

Aksu Z, Isoglu IA (2005) Removal of copper (II) ions from aqueous solution by biosorption onto agricultural waste sugar beet pulp. Process Biochem 40:3031-3044

Alslaibi TM, Abustan I, Ahmad MA, Foul AA (2014) Microwave irradiated and thermally heated olive stone activated carbon for nickel adsorption from synthetic wastewater: a comparative study. Am Inst Chem Eng AIChE J 60(1):237-250

Aydin H, Bulut Y, Yerlikaya C (2008) Removal of copper (II) from aqueous solution by adsorption onto low-cost adsorbents. J Environ Manag 87:37-45

Bhatnagar A, Minocha AK (2010) Biosorption optimization of nickel removal from water using Punica granatum peel waste. Colloids Surf B 76:544-548

Bouguerra W, Ali MBS, Hamrouni B, Dhahbi M (2007) Equilibrium and kinetic studies of adsorption of silica onto activated alumina. Desalination 206:141-146

Chen H, Dai G, Zhao J, Zhong A, Wu J, Yan H (2010) Removal of copper (II) ions by a biosorbent-Cinnamomum camphora leaves powder. J Hazard Mater 177:228-236

Chithra K, Lakshmi S, Jain A (2014) Carica papaya seed as a biosorbent for the removal of $\mathrm{Cr}(\mathrm{VI})$ and $\mathrm{Ni}$ (II) ions from aqueous solution: thermodynamics and kinetic analysis of experimental data. Int J Chem React Eng 12(1):91-102

Dubinin MM (1960) The potential theory of adsorption of gases and vapours for adsorbents with energetically non-uniform surface. Chem Rev 60:235-266

Feng N, Guo X, Liang S (2009) Adsorption study of copper (II) by chemically modified orange peel. J Hazard Mater 164:1286-1292

Flores-Garnica JG, Morales-Barrera L, Pineda-Camacho G, CristianiUrbina E (2013) Biosorption of Ni (II) from aqueous solutions by Litchi chinensis seeds. Bioresour Technol 136:635-643

Ghasemi M, Ghasemi N, Zahedi G, Alwi SRW, Goodarzi M, Javadian H (2014a) Kinetic and equilibrium study of Ni (II) sorption from aqueous solutions onto peganum harmala-L. Int $\mathbf{J}$ Environ Sci Technol 11(7):1835-1844 
Ghasemi M, Naushad M, Ghasemi N, Khosravi-fard Y (2014b) A novel agricultural waste based adsorbent for the removal of $\mathrm{Pb}$ (II) from aqueous solution: kinetics, equilibrium and thermodynamic studies. J Ind Eng Chem 20:454-461

Gutha Y, Munagapati VS, Naushad M, Abburi K (2014) Removal of $\mathrm{Ni}$ (II) from aqueous solution by Lycopersicum esculentum (Tomato) leaf powder as a low cost biosorbent. Desalin Water Treat. doi:10.1080/19443994.2014.880160

Hasar H (2003) Adsorption of nickel (II) from aqueous solution onto activated carbon prepared from almond husk. J Hazard Mater 97:49-57

Hema M, Srinivasan K (2010) Evaluation of coconut oilcake carbon as absorbent for nickel ion: equilibrium and kinetic studies. Asia J Chem 22:2965-2981

Ho YS, Wase DAJ, Forster CF (1996) Removal of lead ions from aqueous solution using sphagnum moss peat as adsorbent. Water SA 22:219-224

ISI (1977) Methods of sampling and tests for activated carbon used for decolourising vegetable oils and sugar solutions. Indian Standards Institution (ISI), 877

Jayaprakasha GK, Chidambara Murthy KN, Uckoo RM, Patil BS (2013) Chemical composition of volatile oil from Citrus limettioides and inhibition of colon cancer cell proliferation. Ind Crops Prod 45:200-207

Kadirvelu K, Namasivayam C (2003) Activated carbon from coconut coirpith as metal adsorbent: adsorption of Cd (II) from aqueous solution. Adv Environ Res 7:471-478

Kannan A, Thambidurai S (2008) Comparative studies on the removal of nickel (II) from aqueous solution by using carbon derived from Palmyra palm fruit seeds and commercial activated carbon. Int J Sci Technol 1(1):93-107

Kobya M, Demirbas E, Senturk E, Ince M (2005) Adsorption of heavy metal ions from aqueous solutions by activated carbon prepared from apricot stone. Bioresour Technol 96(13):1518-1521

Kundu S, Gupta AK (2006) Arsenic adsorption onto iron oxide-coated cement (IOCC): regression analysis of equilibrium data with several isotherm models and their optimization. Chem Eng J 122:93-106

Lakshmipathy R, Sarada NC (2013) Application of watermelon rind as sorbent for removal of nickel and cobalt from aqueous solution. Int J Miner Process 122:63-65

Langmuir I (1918) The adsorption of gases on plane surfaces of glass, mica and platinum. J Am Chem Soc 40:1361-1403

Lee CH, Lee C-H (2005) A study on nickel hydroxide crystallization characteristics. Korean J Chem Eng 22(5):712-716

Lin SH, Lai SL, Leu HG (2000) Removal of heavy metals from aqueous solution by chelating resin in a multistage adsorption process. J Hazard Mater 76(15):139-153

Madhavakrishnan S, Manickavasagam K, Rasappan K, Syed Shabudeen PS, Venkatesh R, Pattabhi S (2008) Ricinus communis pericap activated carbon used as an adsorbent for the removal of $\mathrm{Ni}$ (II) from aqueous solution. E-J Chem 5(4):761-769

Mahvi AH (2008) Application of agricultural fibers in pollution removal from aqueous solution. Int $\mathrm{J}$ Environ Sci Technol $5(2): 275-285$

Malkoc E, Nuhoglu Y (2005) Investigations of nickel (II) removal from aqueous solutions using tea factory waste. J Hazard Mater B127:120-128

Michelson LD, Gideon PG, Pace EG, Kutal LH (1975) US Department Industry, Office of water Research and Technology, Bulletin, No.74

Mouni L, Merabet D, Bouzaza A, Belkhiri L (2011) Adsorption of $\mathrm{Pb}$ (II) from aqueous solutions using activated carbon developed from apricot stone. Desalination 276:148-153
Mousavi HZ, Seyedi SR (2011) Nettle ash as a low coast adsorbent for the removal of nickel and cadmium from wastewater. Int $\mathbf{J}$ Environ Sci Technol 8(1):195-202

Nagashanmugam KB, Srinivasan K (2010) Evaluation of carbons derived from gingelly oil cake for the removal of lead (II) from aqueous solutions. J Environ Sci Eng 52(4):349-360

Nwuche CO, Ugoji EO (2008) Effects of heavy metal pollution on the soil microbial activity. Int J Environ Sci Technol 5(2):409-414

Onundi YB, Mamun AA, Al Khatib MF, Ahmed YM (2010) Adsorption of copper, nickel and lead ions from synthetic semiconductor industrial wastewater by palm shell activated carbon. Int J Environ Sci Technol 7(4):751-758

Ozbay N (2009) Adsorption of Ni (II) ions from aqueous solution by pyrolytic chars derived from the cottonseed cake. Energy Sour A Recover Util Environ Eff 31(14):1271-1279

Pandey PK, Choubey S, Verma Y, Pandey M, Kalyan-Kamal SS, Chandrashekhar K (2007) Biosorptive removal of Ni (II) from wastewater and industrial effluent. Int J Environ Res Publ Health 4:332-339

Prasad AGD, Abdullah MA (2009) Biosorption potential of potato peel waste for the removal of nickel from aqueous solutions: equilibrium and kinetic studies. Int J Chem Eng Res 2:77-87

Prasad MNV, Freitas H (2000) Removal of toxic metals from solution by leaf, stem and root phytomass of Quercus ilex L. (holly oak). Environ Pollut 110:277-283

Rajesh Y, Pujari M, Uppaluri R (2014) Equilibrium and kinetic studies of $\mathrm{Ni}$ (II) adsorption using pine apple and bamboo stem based adsorbents. Sep Sci Technol 49(4):533-544

Rao RAK, Ikram S (2011) Sorption studies of $\mathrm{Cu}$ (II) on gooseberry fruit (emblica officinalis) and its removal from electroplating wastewater. Desalination 277:390-398

Reddad Z, Gerente C, Andres Y, Le Cloirec P (2002) Adsorption of several metal ions onto a low-cost biosorbent: kinetic and equilibrium studies. Environ Sci Technol 36(9):2067-2073

Savolainen H (1996) Biochemical and clinical aspects of nickel toxicity. Rev Environ Health 11(4):167-173

Senthil Kumar P, Ramalingam S, Abhinaya RV, Thiruvengadaravi KV, Baskaralingam P, Sivanesan S (2011a) Lead (II) adsorption onto sulphuric acid treated cashew nut shell. Sep Sci Technol 46:2436-2449

Senthil Kumar P, Ramalingam S, Dinesh Kirupha S, Murugesan A, Vidhyadevi T, Sivanesan S (2011b) Adsorption behaviour of nickel (II) onto cashew nut shell: equilibrium, thermodynamics, kinetics, mechanism and process design. Chem Eng J 167(1):122-131

Senturk HB, Ozdes D, Duran C (2010) Biosorption of rhodamine 6G from aqueous solutions onto almond shell (Prunus dulcis) as a low cost biosorbent. Desalination 252:81-87

Shrestha RM, Varga Margit, Varga I, Yadav AP, Pokharel BP, Pradhananga RR (2013a) Removal of Ni (II) from aqueous solution by adsorption onto activated carbon prepared from Lapsi (Choerospondias axillaris) seed stone. J Inst Eng 9(1):166-174

Shrestha S, Son G, Lee SH, Lee TG (2013b) Isotherm and thermodynamic studies of $\mathrm{Zn}$ (II) adsorption on lignite and coconut shell-based activated carbon fiber. Chemosphere 92:1053-1061

Shroff KA, Vaidya VK (2011) Kinetics and equilibrium studies on biosorption of nickel from aqueous solution by dead fungal biomass of Mucor hiemalis. Chem Eng J 171(3):1234-1245

Subbaiah MV, Vijaya Y, Kumar NS, Reddy AS, Krishnaiah A (2009) Biosorption of nickel from aqueous solutions by Acacia leucocephala bark: kinetics and equilibrium studies. Colloids Surf B 74:260-265 
Suganthi N, Srinivasan K (2011) Adsorptive removal of nickel and lead ions from aqueous solutions using phosphorylated tamarind nut carbon. J Environ Sci Eng 53:163-174

Terzyk AP (2001) The influence of activated carbon surface chemical composition on the adsorption of acetaminophen (paracetamol) in vitro. Part II. TG, FTIR, and XPS analysis of carbons and the temperature dependence of adsorption kinetics at the neutral $\mathrm{pH}$. Colloids Surf A Physicochem Eng Asp 177:23-45

Thamilarasu P, Sivakumar P, Karunakaran K (2011) Removal of Ni (II) from aqueous solutions by adsorption onto Cajanus cajan $\mathrm{L}$ milsp seed shell activated carbons. Ind $\mathrm{J}$ Chem Technol 18(5):414-420

Ugurlu M, Kula I, Karaoglu MH, Arslan Y (2009) Removal of Ni (II) ions from aqueous solutions using activated carbon prepared from olive stone by $\mathrm{ZnCl}_{2}$ activation. Environ Prog Sustain Energy 28:547-557

Venkata Ramana DK, Harikishore Kumar Reddy D, Naresh Kumar B, Harinath Y, Seshaiah K (2012) Removal of nickel from aqueous solutions by citric acid modified ceiba pentandra hulls: equilibrium and kinetic studies. Can J Chem Eng 90(1):111-119

Wang G, Li A, Li M (2010) Sorption of nickel ions from aqueous solutions using activated carbon derived from walnut shell waste. Desalin Water Treat 16:282-289

Weber TW, Chakkravorti RK (1974) Pore and solid diffusion models for fixed bed adsorbers. Am Inst Chem Eng J 20:228

Wilson K, Yang H, Seo CW, Marshalll WE (2006) Select metal adsorption by activated carbon made from peanut shells. Bioresour Technol 97:2266-2270

Wu Y, Zhang S, Guo X, Huang H (2008) Adsorption of chromium (III) on lignin. Bioresour Technol 99:7709-7715

Zewail TM, El-Garf SAM (2010) Preparation of agriculture reside based adsorbents for heavy metal removal. Desalin Water Treat 22:363-370 